\title{
Electrochemical DNA Biosensors Based on Gold Nanoparticles / Cysteamine / Poly(glutamic acid) Modified Electrode
}

\author{
Yuzhong Zhang*, Keying Zhang, Haiyan Ma
}

Key Laboratory of Functional Molecular Solids, Anhui Normal University, Wuhu 241000, P.R. China.

*Corresponding Author

Dr. Yuzhong Zhang

College of Chemistry and Materials Science,

Anhui Normal University, Wuhu 241000, P.R. China

Tel: +86-553-3869303, Fax: +86-553-3869303.

E-mail: zhyz65@mail.ahnu.edu.cn

Received: 5 December 2008; $\mid$ Revised: 29 January 2009; $\mid$ Accepted: 5 February 2009

\begin{abstract}
In the present study, an electrochemical DNA sensing strategy for highly sensitivity detection of DNA hybridization was reported based on a gold nanoparticles (AuNPs) / cysteamine (Cys) / poly glutamic acid (PGA) modified electrode. A glassy electrode was first modified with the polymer film by cyclic voltammetry $(\mathrm{CV})$, and then AuNPs were immobilized on the surface of PGA with Cys as a linker, to which probe DNA was covalently linked onto the surface of AuNPs through a 5'-thiol-linker. The DNA hybridization events were monitored by differential pulse voltammetry (DPV) measurement of the intercalated adriamycin. Under optimal conditions, the reduction peak currents were linearly increased with increasing the concentration of complementary target DNA from $9.0 \times 10^{-11}$ to $4.8 \times 10^{-9} \mathrm{M}$ with a detection limit of $4.2 \times 10^{-11} \mathrm{M}$. This DNA biosensor exhibited excellent selectivity, reproducibility and stability in DNA hybridization assay.
\end{abstract}

Keywords: DNA hybridization; Gold nanoparticles; Glutamic acid; DNA biosensor.

\subsection{Introduction}

In recent years, the detection of specific DNA sequences has attracted considerable attention of chemists and biologists due to its potential applications in disease diagnosis, epidemic prevention and forensic identification. As a result, various techniques have been developed for the detection of specific DNA sequences, including electrochemistry $[1,2]$, fluorescence $[3,4]$, radiochemical assays $[5,6]$, surface plasmon resonance spectroscopy $[7,8]$ and quartz crystal microbalance [9, 10]. Among these, electrochemical detection assays have the advantage of being simple, reliable, inexpensive, sensitive, and selective for genetic detection. A variety of electrochemical approaches to detecting DNA hybridization assay have been reported. Xia 
and his colleagues have fabricated a DNA biosensor based on silica-nanoparticle interface [11-12]. Li and his colleagues have fabricated a controllable DNA hybridization sensor based on magnetic nanoparticles [13]. Some reviews have recently reported electrochemical DNA sensors [14-17].

Biosensors consist of two main parts: a biorecognition interface, which enables the selective detection of the analyte, and a transducer, which converts the recognition event into an electronic signal [18, 19]. For electrochemical DNA sensors, the transducer is an electrode (constructed of gold or glassy carbon) onto which DNA, as the biorecognition species, is immobilized. As is well known, the sensitivity and lifetime of DNA sensors depends on the immobilization of DNA probes onto electrode surfaces. Several methods of immobilizing DNA probes onto electrode surfaces have been reported, including physical adsorption, entrapment in a gel or polymer, covalent binding, cross-linking and electrochemical polymerization. One of these promising approaches is electrochemical polymerization using conducting polymers [19-25] such as polypyrrole [24, 25], and this kind of polymeric DNA biosensor has good sensitivity and stability.

It is reported that sensitive detection of specific DNA sequences on the basis of the hybridization reaction can be improved utilizing target or signal amplification strategies. Most of the recent developments in ultrasensitive detection of DNA have been based on the use of nanomaterials and nanotechnologies. The use of nanomaterials, nanoparticles [26-28], nanotubes [29-31] and nanowires [32,33] as a medium for signal amplification has provided many opportunities for the advance of biomolecule and gene detection.

Previously, we reported a type of electrochemical DNA biosensor based on multilayer films fabricated by LBL covalent attachment of multi-walled carbon nanotubes and GNPs [34, 35]. This strategy improves the stability of multilayer films and provides an efficient way to produce complex layered biosensor structure, however the preparation process is complex. Subsequently, we developed an DNA biosensor based on a silver nanoparticle / poly(3-(3-pyridyl) acrylic acid) / carbon nanotube modified electrode. This DNA sensor also has good selectivity and sensitivity [36]. In this work, we have fabricated an ssDNA /AuNPs / Cys / PGA electrochemical biosensor. Differential pulse voltammetry (DPV) was used to detect DNA hybridization using adriamycin as an electroactive indicator. The experimental results show that the DNA biosensor has good selectivity, sensitivity, stability and reusability. The approach to probing DNA immobilization and hybridization with target oligonucleotides is illustrated in Scheme 1.

\subsection{Experimental}

\subsection{Reagents}

Glutamic acid was purchased from Shanghai Biochemical Institute. Hydrogen tetrachloroaurate hydrate $\left(\mathrm{HAuCl}_{4} \cdot 3 \mathrm{H}_{2} \mathrm{O}\right)$, trisodium citrate, 2mercaptoethylamine hydrochloride (Cysteamine), sodium dodecyl sulfate (SDS), Nhydroxysuccinimide (NHS) and 1-ethyl-3-(3dimethylaminopropyl) carbodiimide (EDC) were purchased from Alfa Aesar Co, Ltd. (Tianjing, China). Adriamycin hydrochloride was obtained from the National Institute for the Control of Pharmaceutical and Biological Products (Beijing, China). $\mathrm{NaOH}, \mathrm{HNO}_{3}$ and $\mathrm{H}_{3} \mathrm{PO}_{4}$ were obtained from Nanjing Chemical Reagent Co, Ltd. (Nanjing, China). Potassium ferricyanide / ferrocyanide were purchased from Shanghai Reagent Company (Shanghai, China). All oligonucleotide fragments used in this work were purchased from Shanghai Sangon Biological Engineering Technology \& Services Co., Ltd. (Shanghai, China), and sequences of all oligonucleotides are listed as follows.

Probe sequence: $\mathrm{SH}-\left(\mathrm{CH}_{2}\right)_{6}{ }^{-5}$ '-AAG CGG AGG ATT GAC GAC TA-3'

Complementary sequence: 5'-TAG TCG TCA ATC CTC CGC TT-3'

Non-complementary sequence: 5'-AAG CGG AGG ATT GAC GAC TA-3'

Three-base mismatched sequence: 5'-TAG ACG TCA TTC CTC CCC TT-3'

Stock solutions of DNA were prepared in PBS solution $(\mathrm{pH} 7.0)$ and stored at $-20^{\circ} \mathrm{C}$ until used. The buffer solutions employed in this study 
are as follows: $0.01 \mathrm{M}$ PBS $(0.1 \mathrm{M} \mathrm{NaCl}+0.01 \mathrm{M}$ sodium phosphate buffer solution, $\mathrm{pH} 7.0), 0.1 \mathrm{M}$ PBS (0.1 M sodium phosphate buffer solution, $\mathrm{pH}$
7.0). All chemicals were of analytical grade and used without further purification. All solutions were prepared with twice-quartz-distilled water.

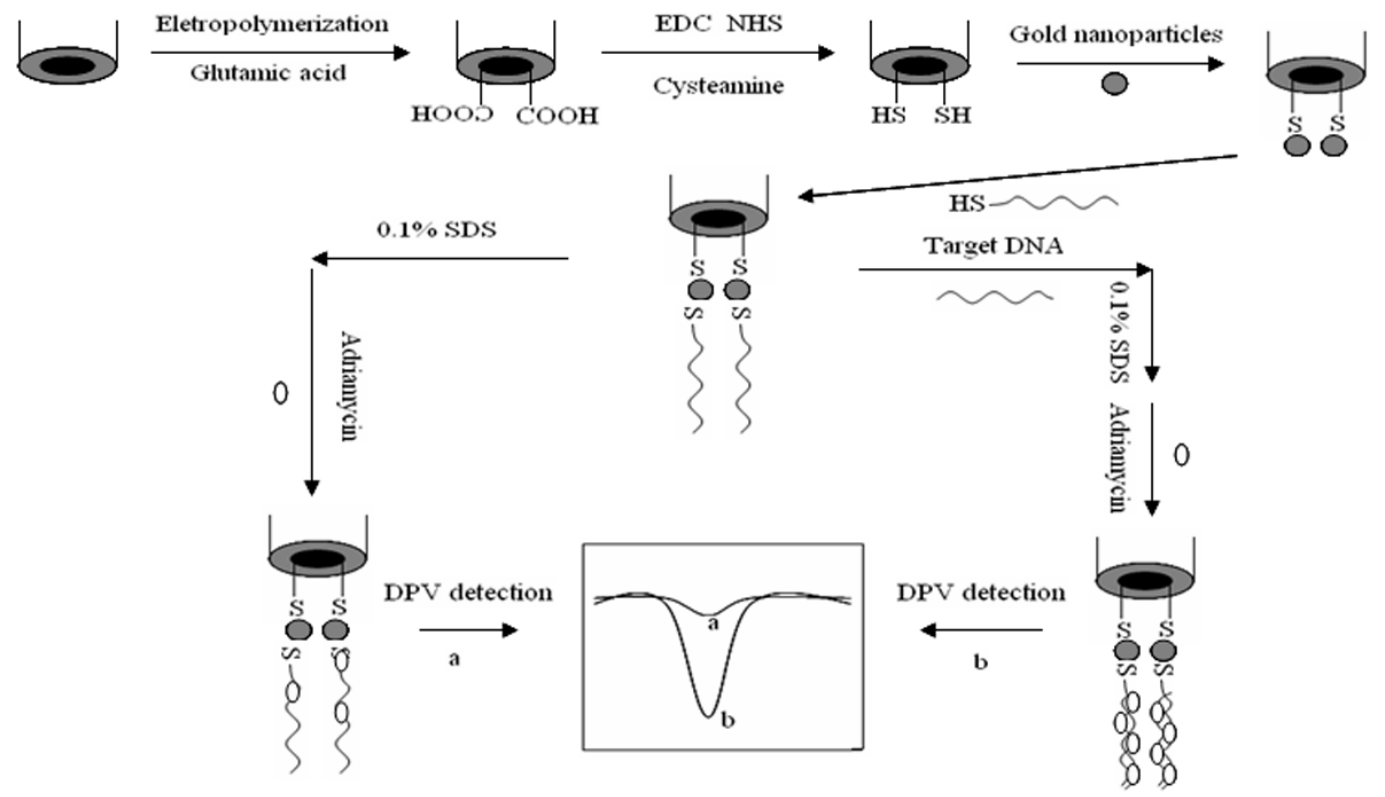

Scheme 1. Schematic representation of the immobilization and hybridization detection of probe DNA.

\subsection{Apparatus}

All electrochemical measurements were performed on a CHI 650C electrochemical workstation (Shanghai Chenhua Instruments Co., China). The three-electrode system used consisted of the working electrode of interest, a saturated calomel electrode (SCE) reference electrode, and a platinum wire auxiliary electrode. CV and DPV were carried out in a $10 \mathrm{~mL}$ electrochemical cell, which was degassed with high-purity nitrogen for 30 minutes. All the potentials given in this paper were referenced to SCE. Electrochemical Impedance Spectra (EIS) was performed in the presence of $5.0 \mathrm{mM}\left[\mathrm{Fe}(\mathrm{CN})_{6}\right]^{3-4-}$ as a redox probe in the frequency range between 1 and $10^{5}$ $\mathrm{Hz}$ at the formal potential of $0.199 \mathrm{~V}$. The AC voltage amplitude was $5 \mathrm{mV}$. The morphologies of various modified electrode surfaces were investigated by scanning electron microscopy (SEM) using a JEOLJSM-6700F microscope (Hitachi, Japan).

\subsection{Synthesis of Gold Nanoparticles}

AuNPs were prepared according to the literature [39] with a little modification. Breifly, $100 \mathrm{~mL}$ sample of aqueous $\mathrm{HAuCl}_{4}(0.01 \%)$ was brought to a boil, and $2.5 \mathrm{~mL}$ of $1 \%$ trisodium citrate solution was added with vigorous stirring. The mixed solution was stirred for $30 \mathrm{~min}$ and allowed to return to room temperature under stirring. The resulting solution of GNPs was examined using a UV-vis spectrometer, which yielded a strong absorption peak at $518 \mathrm{~nm}$, characteristic of monodispersed gold colloid. The diameter of the AuNPs was about $16 \mathrm{~nm}$ as measured by transmission electron microscopy (picture not shown). The obtained colloidal gold solution was stored in dark glass bottles at $4{ }^{\circ} \mathrm{C}$ for further use.

\subsection{Fabrication of ssDNA/ AuNPs /Cys /PGA probe electrode}

\subsubsection{Preparation of PGA Modified Electrode}

Prior to modification, the bare GCE was polished to a mirror-like surface with Gamma alumina suspensions $(1.0 \mu \mathrm{m}, 0.25 \mu \mathrm{m}$ and $0.05 \mu \mathrm{m}$, respectively). Then, the electrode was successively ultrasonically washed in ethanol and twice-quartz-distilled water for $3 \mathrm{~min}$, respectively. The PGA modified electrode was prepared according to previous reports [37, 38]. 
Briefly, a clean glassy electrode was immersed into $0.02 \mathrm{M}$ glutamic acid solution in $0.1 \mathrm{M}$ PBS $(\mathrm{pH} 7.0)$ and subjected to cyclic potential scans (15 cycles from -1.0 to $+2.0 \mathrm{~V}$ with a scan rate of $100 \mathrm{mV} / \mathrm{s}$ ). The free polar carboxylic acid groups layer was deposited on the surface of electrode. Afterwards, the electrode was gently washed with twice-quartz-distilled water and ready for use.

\subsubsection{Preparation of ssDNA /AuNPs /Cys /PGA Modified Electrode}

The PGA modified electrode was activated for $1 \mathrm{~h}$ in 1:1(v/v) EDC / NHS mixture $(10 \mathrm{mM}$ EDC and $10 \mathrm{mM}$ NHS, pH 5.0), and allowed to react with a $0.5 \mathrm{M}$ cysteamine solution for $40 \mathrm{~min}$. This process yields thiol groups on self-assembled monolayer film. Next, the Cys/PGA modified electrode was immersed into AuNPs solution for $12 \mathrm{~h}$ in a refrigerator. The resulting electrode was carefully washed with twice-quartz-distilled water and allowed to dry at room temperature. Finally the AuNPs /Cys/PGA modified electrode was immersed in a $1.0 \times 10^{-6} \mathrm{M}$ ssDNA probe solution for $6 \mathrm{~h}$, which gives a probe ssDNA selfassembled layer via $\mathrm{S}-\mathrm{Au}$ binding. The probemodified electrode was immersed into $0.1 \%$ SDS for $10 \mathrm{~min}$ and washed with twice-quartz-distilled water and 0.1 M PBS for three times, respectively. The obtained electrode was denoted as a ssDNA / AuNPs /Cys /PGA modified electrode.

\subsection{Electrochemical Detection of DNA Hybridization}

The hybridization reaction was performed by immersing the probe DNA modified electrode into $0.01 \mathrm{M}$ PBS solution containing varying concentrations of target DNA for $20 \mathrm{~min}$ at $40^{\circ} \mathrm{C}$. The hybridized double-stranded DNA electrode was next immersed into $0.1 \%$ SDS for $10 \mathrm{~min}$, then it was immersed in a $0.01 \mathrm{M}$ PBS solution containing $1.0 \times 10^{-6} \mathrm{M}$ adriamycin for $10 \mathrm{~min}$, finally it was washed with twice-quartz-distilled water and 0.1 M PBS for three times to remove physically absorbed adriamycin.

The DNA hybridization was assessed with DPV peak current of adriamycin in $0.1 \mathrm{M}$ PBS (pH 7.0). The concentration of target oligonucleotides was quantified by the increase of reduction peak current $(\Delta \mathrm{I})$ of adriamycin, which was subtracted from the reduction peak current generated at the ssDNA/ AuNPs /Cys/PGA modified electrode.

\subsection{Results and Discussions}

\subsection{Characterization of the different modified electrode}

The bare glassy electrode, PGA and AuNPs/Cys/ PGA modified electrode were characterized by SEM, which are shown in Figure 1, from which we can observe that AuNPs were equably coated onto the surface of electrode. The result indicated that AuNPs /Cys/ PGA modified electrode had been successfully fabricated.
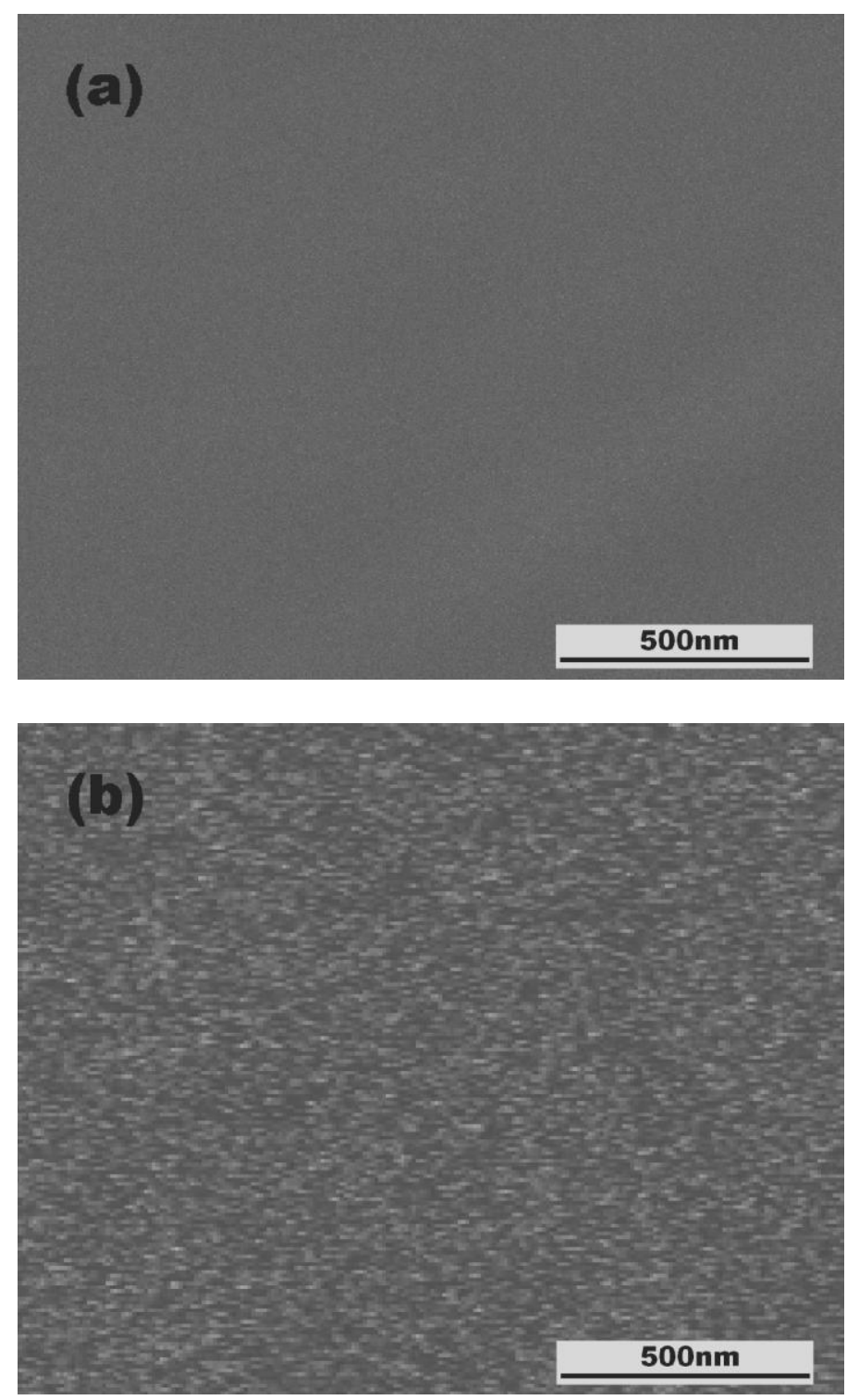


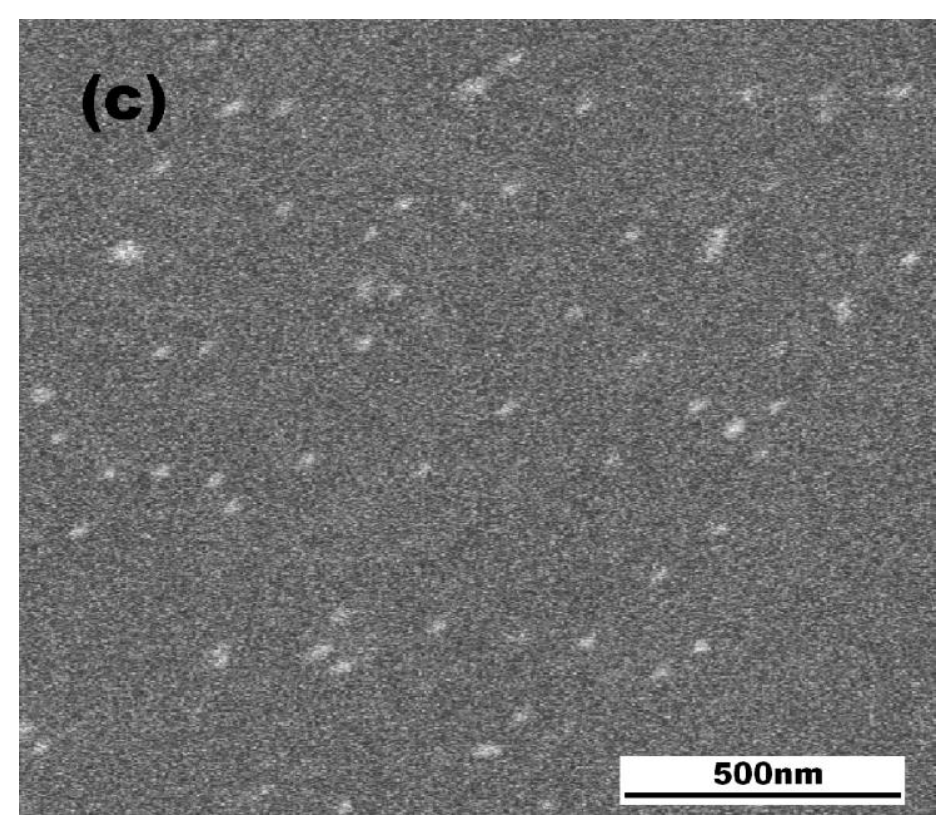

Figure 1. SEM pictures of the bare GCE (a), Cys/PGA (b) and AuNPs /Cys/PGA (c).
Previous studies have revealed that the fabrication of polymeric film and assembly of nucleic acids on electrodes can be indicated by EIS. Figure. 2 shows Nyquist plots of impedance for bare GCE (Figure 2a), GCE modified with PGA (Figure 2b), GCE modified with AuNPs /Cys/PGA (Figure 2c) and after immobilization of probe DNA (Figure 2d). In EIS, the semicircle diameter corresponds to the electron transfer resistance $\left(R_{\mathrm{et}}\right)$. We can observe there is a small $\mathrm{R}_{\mathrm{et}}$ at the bare GCE or PGA modified electrode. When AuNPs were immobilized on the electrode, the $\mathrm{R}_{\mathrm{et}}$ is increased. This increase is a result of AuNPs having a negative charge which can stop $\left[\mathrm{Fe}(\mathrm{CN})_{6}\right]^{3-/ 4-}$ from approaching the surface of electrode. When the DNA probe was immobilized onto the modified electrode, the $\mathrm{R}_{\mathrm{et}}$ is increased greatly, as the negatively charged phosphate skeletons of DNA cause an electrostatic repulsion to $\left[\mathrm{Fe}(\mathrm{CN})_{6}\right]^{3-/ 4}$.

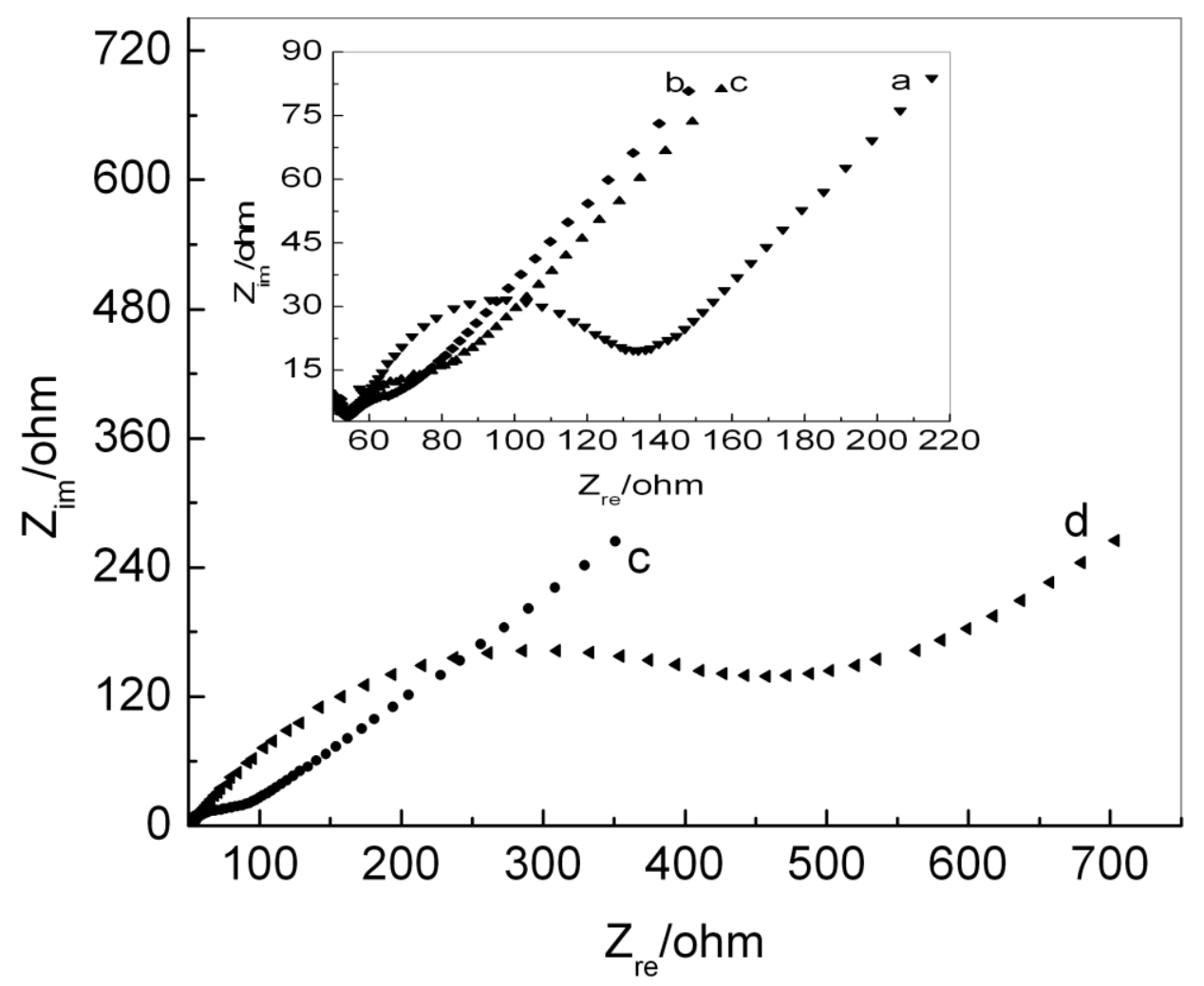

Figure 2. Nyquist plots obtained for different electrodes: the bare GCE (a), the PGA (b), the AuNPs /Cys/PGA (c) and the ssDNA/ AuNPs /Cys/PGA (d). 
In this work, $\mathrm{CV}$ response of Adriamycin at different electrodes was used to investigate the immobilization of probe DNA. When AuNPs were introduced onto a PGA electrode (data not shown), the peak currents of adriamycin were greatly enhanced with respect to the bare electrode. After probe DNA was introduced to the surface of AuNPs /Cys /PGA, a much larger voltammetric response of adriamycin was observed. This larger voltammetric can be attributed to the electrostatic interaction between the negatively charged phosphate backbone of DNA and adriamycin. This result indicates the AuNPs thin film could provide a good platform for probe DNA immobilization.

\subsection{Optimization of Experiment Conditions}

\subsubsection{Hybridization Time}

Figure 3 shows the influence of the DNA hybridization time on the peak current of adriamycin. It is apparent that the reduction current rapidly increased initially with a hybridization time from 0 to $10 \mathrm{~min}$, then increased slightly from 10 to 20 min and remained constant after $20 \mathrm{~min}$. This indicated that the hybridization reaction was dominantly completed after $20 \mathrm{~min}$. Considering the sensitivity and assay time, 20 min was chosen as the hybridization time in this work.

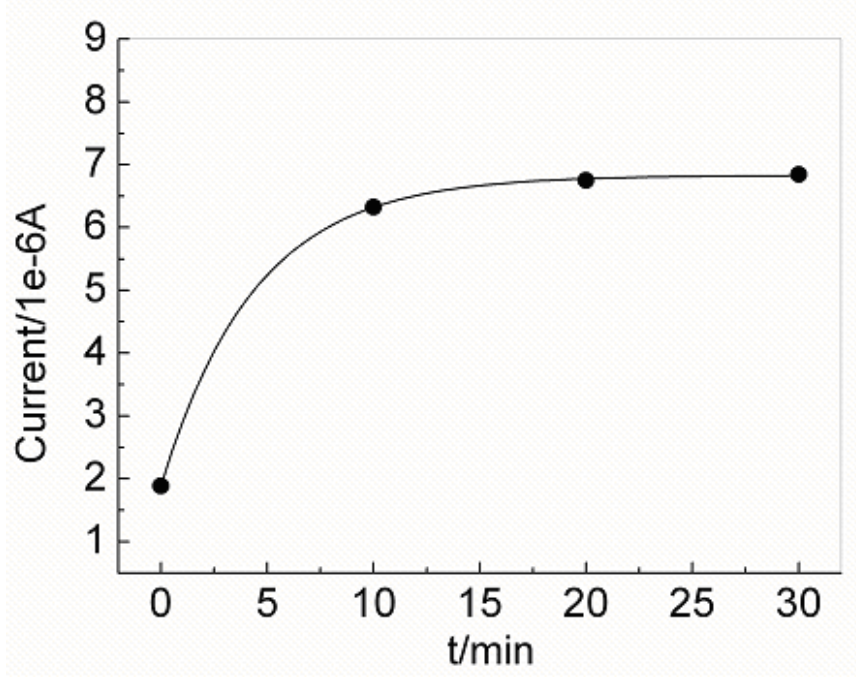

Figure 3. The effect of DNA hybridization time on the reduction peak current of adriamycin
The DNA biosensor was incubated in 0.01 M PBS (pH 7.0) containing $4.8 \times 10^{-8} \mathrm{M}$ cDNA at $40{ }^{\circ} \mathrm{C}$ for different times. The DPV measurements were completed in $0.1 \mathrm{M} \mathrm{pH} \mathrm{7.0} \mathrm{PBS.} \mathrm{The} \mathrm{DPV}$ parameters: initial potential: $0.7 \mathrm{~V}$; terminal potential: $0 \mathrm{~V}$; pulse amplitude: $50 \mathrm{mV}$; pulse period: $0.2 \mathrm{~s}$; pulse width: $50 \mathrm{~ms}$.

\subsubsection{Accumulation Time of Adriamycin}

The effect of accumulation time of adriamycin was investigated by DPV measurements of adriamycin at hybridized electrodes which were incubated in $1.0 \times 10^{-6} \mathrm{M}$ adriamycin for varying times. The results are shown in Figure 4. It can be seen the peak current of adriamycin increased significantly with the increasing accumulation time from 0 to $10 \mathrm{~min}$. When the accumulation time is higher than 10 min, the peak current of adriamycin remains relatively constant, so 10 min was selected as the optimum accumulation time.

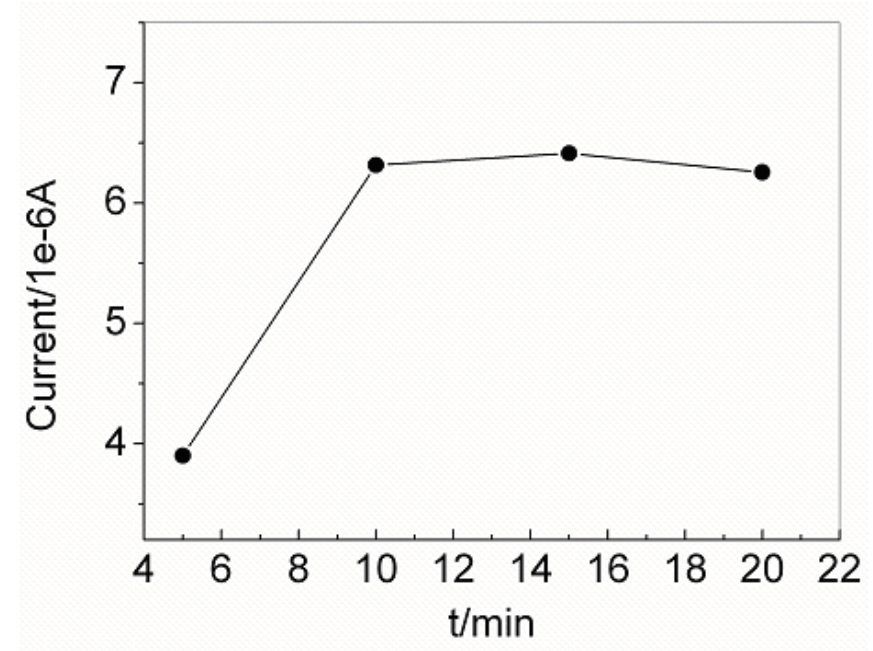

Figure 4. The effect of accumulation time on the reduction peak current of adriamycin.

The hybridized electrode was incubated in 0.01 M PBS (pH 7.0) containing $1.0 \times 10^{-6} \mathrm{M}$ adriamycin for various times. The DPV measurements were completed in $0.1 \mathrm{M} \mathrm{pH} 7.0$ PBS. The DPV parameters were the same as in Figure 3.

\subsection{Analytical performance}

Under optimal conditions, the sensitivity of the DNA sensor was investigated using an immobilized DNA probe to hybridize with 
different concentrations of the cDNA. Figure 5 displays DPVs recorded of adriamycin as redox intercalator when the immobilized probe hybridized with different concentrations of the cDNA. We can observed the reduction peak current of adriamycin increased with the concentration of the cDNA increased, and the increases of peak current are linear with the concentration of the cDNA in the range from $9.0 \times 10^{-11}$ to $4.8 \times 10^{-9} \mathrm{M}$ (shown in the inset of Figure. 5) The regression equation was $\Delta \mathrm{I}(\mu \mathrm{A})=$ $0.5797+0.058 \mathrm{C} \quad(c:$ the concentration of complementary sequence $\left(10^{-10} \mathrm{M}\right), i$ : the peak current of adriamycin, $\mu \mathrm{A}$ ), and a regression coefficient $\left(\mathrm{r}^{2}\right)$ of 0.9907 . A detection limit of $4.2 \times 10^{-11} \mathrm{M}$ was achieved $(S / N=3)$.
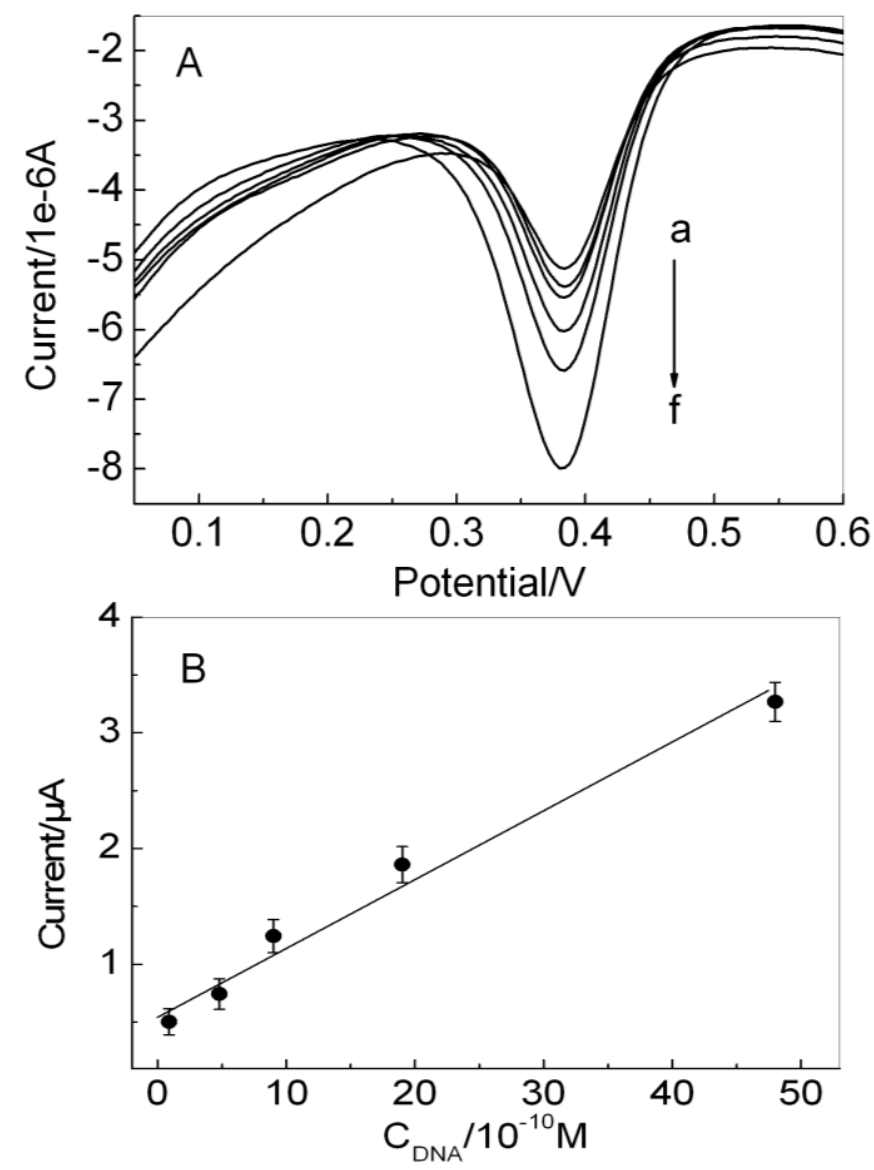

Figure.5. A) DPV responses of the intercalated adriamycin recorded for the ssDNA/ AuNPs /Cys/PGA/GCE which hybridized with different concentrations of cDNA: $0.0 \mathrm{M}$ (a), $9.0 \times 10^{-11} \mathrm{M}$ (b), $4.8 \times 10^{-10} \mathrm{M}$ (c), $9.0 \times 10^{-10} \mathrm{M}(\mathrm{d}), 1.9 \times 10^{-9} \mathrm{M}$ (e), $4.8 \times 10^{-9} \mathrm{M}$ (f). B): The peak current vs. the concentration of cDNA. The DPV parameters were the same as in Figure. 3.
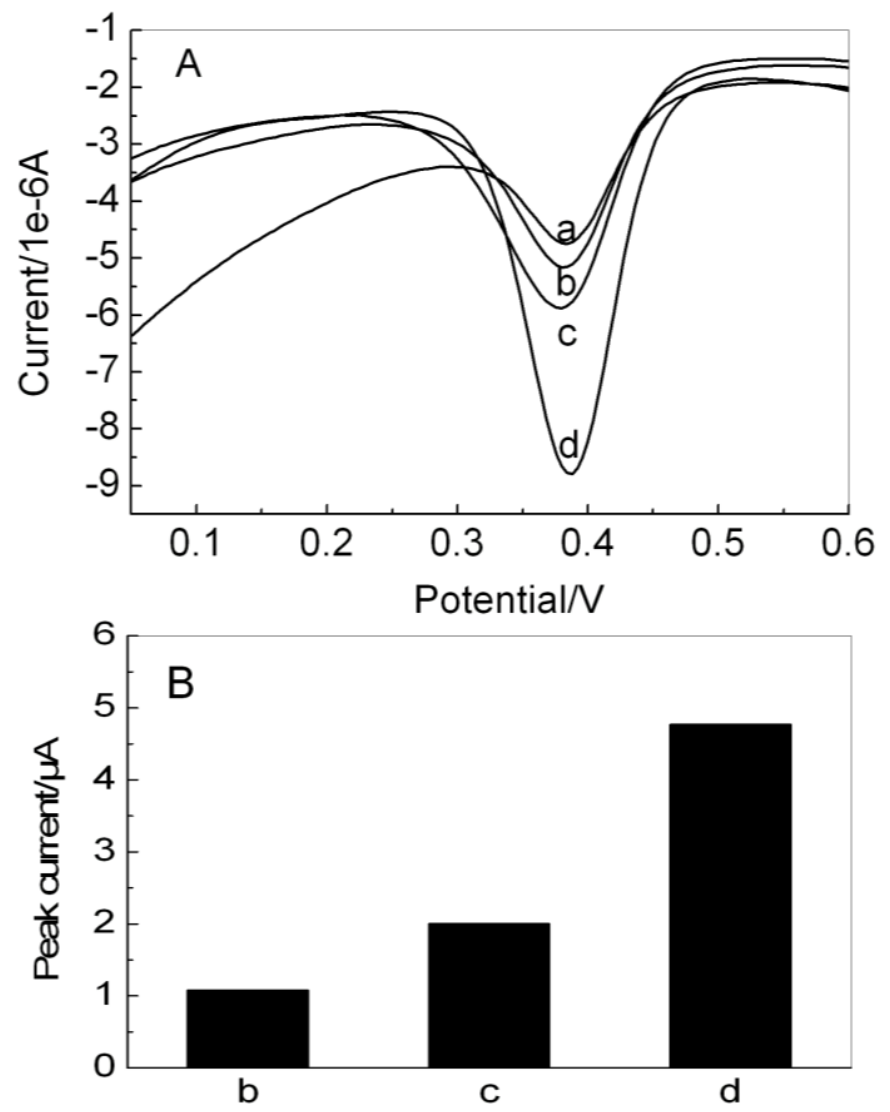

Figure 6. A)The DPV responses of adriamycin recorded for ssDNA/ AuNPs /Cys/PGA without hybridized (a); hybridized with noncomplementary DNA (b); hybridized with threebase mismatched DNA (c); hybridized with cDNA (d). B) Corresponding histograms of the reduction peak currents. The concentration of DNA was $4.8 \times 10^{-8} \mathrm{M}$. The DPV parameters were the same as in Figure 3.

Selectivity is a crucial factor to be considered for a DNA biosensor. In this work, it was also evaluated using its complete complementary, three-base mismatched and non-complementary DNA sequences. As it is shown in Figure 6, when non-complementary and three-base mismatched DNA sequences exist, the signal of adriamycin was lower (curves b and $\mathrm{c}$ in Figure 6), when its complete cDNA sequence exists, the signal of adriamycin is obviously increased. So the DNA sensor can distinguish between three-base 
mismatched DNA sequences and cDNA sequences. This result suggests that the fabricated DNA sensor has excellent selectively.

We also compare the performances of different electrochemical DNA sensors with this work and results are shown in table 1 . From the table 1, we know can observe this DNA sensor reported in this study has shorter hybridization time and lower detection limit. In conclusion, the proposed DNA sensor exhibits good analytical performance for the specific sequences in DNA detection.

\begin{tabular}{|c|c|c|c|c|c|}
\hline \multirow[t]{2}{*}{ The DNA sensor } & \multirow[t]{2}{*}{ Detect technique } & \multicolumn{2}{|c|}{ linear detection } & \multicolumn{2}{|c|}{ Hybridization } \\
\hline & & range $(\mathrm{nM})$ & limit $(n M)$ & time (min) & Reference \\
\hline $\mathrm{PPy} / \mathrm{DNA} / \mathrm{CNT} / \mathrm{GCE}$ & DPV & $0.1-1000$ & 0.05 & 180 & {$[40]$} \\
\hline DNA/PICA/GCE & $\mathrm{CV}$ & $3.34-10.6$ & 1.0 & 45 & [41] \\
\hline Polypyrrole/DNA/MWCNTs & DPV & $0.1-10$ & 0.085 & 30 & {$[42]$} \\
\hline \multicolumn{6}{|l|}{ Paste electrode } \\
\hline DNA/ AuNPs / cys/PGA & DPV & $0.09-4.8$ & 0.042 & 20 & this work \\
\hline
\end{tabular}

Table 1 Comparison of analytical performances of several electrochemical DNA sensors

\subsection{Reproducibility, Regeneration and Stability of the DNA Sensor}

The reproducibility of the DNA sensor was also investigated. Three DNA sensors, which were fabricated independently at the same conditions, were used to detect $4.8 \times 10^{-8} \mathrm{M}$ complementary DNA, respectively. The reduction peak current of adriamycin were $6.846 \times 10^{-6} \mathrm{~A}, 6.656 \times 10^{-6} \mathrm{~A}$, $6.256 \times 10^{-6} \mathrm{~A}$, respectively, which gave an average value $6.586 \times 10^{-6}$ A with a relative standard deviation (R.S.D.) of $4.6 \%$. This result suggests that the DNA sensor is reproducible.

The regeneration of the DNA sensor was also investigated by immersing hybridized electrodes in hot water $\left(80{ }^{\circ} \mathrm{C}\right)$ for $5-10 \mathrm{~min}$, which completely removed hybridized DNA via thermal denaturation [43]. The reduction peak current of adriamycin was $6.656 \times 10^{-6} \mathrm{~A}$ at the first detection. The DNA sensor was regenerated according to the above description. The reduction peak currents of adriamycin of three times successive DNA sensor regeneration were $6.413 \times 10^{-6} \mathrm{~A}, 6.316 \times 10^{-6} \mathrm{~A}$, $6.238 \times 10^{-6} \mathrm{~A}$, respectively. The third regenerated electrode has $94.0 \%$ response of the initial electrode, indicating the proposed DNA sensor was of good reusability.

When the DNA sensor was stored in the refrigerator at $4{ }^{\circ} \mathrm{C}$ and measured after ten days, it kept about $86.2 \%$ of its original response. This indicates that the proposed DNA sensor has good stability.

\subsection{Conclusions}

In present work, we introduce an electrochemical DNA sensor, and the DNA sensor displays good selectivity and high sensitivity. The experiment result indicates the DNA sensor has a fast response time, easy fabrication, and is capable of detecting a three-base mismatched DNA sequence assay.

\section{Acknowledgements}

This project was supported by the National Nature Science Foundation of China (NSFC) (No. 20675002) and Program for Innovative Research Team in Anhui Normal University. 


\section{References}

1. Kavanagh, P.; Leech, D. Redox polymer and probe DNA tethered to gold electrodes for enzyme-amplified amperometric detection of DNA hybridization, Anal Chem, 2006, 78, 2710-2716.

2. Flechsig, G.U.; Reske, T. Electrochemical detection of DNA hybridization by means of osmium tetroxide complexes and protective oligonucleotides, Anal Chem, 2007, 79, 21252130.

3. Benoit, V.; Steel, A.; Torres, M.; Yu, Y.Y.; Yang, H.J.; Cooper, J. Evaluation of threedimensional microchannel glass biochips for multiplexed nucleic acid fluorescence hybridization assays, Anal Chem, 2001, 73, 2412-2420.

4. Dharmadi, Y.; Gonzales, R. DNA microarrays: experimental issues, data analysis, and application to bacterial, Biotechnol Prog, 2004, 20, 1309-1324.

5. Jilbert, A.R. In situ hybridization protocols for detection of viral DNA using radioactive and nonradioactive DNA probes, Methods Mol Biol, 2000, 123, 177-193.

6. Barlet, V.; Cohard, M.; Thelu, M.A.; Chaix, M.J.; Baccard, C.; Zarski, J.P.; Seigneurin, J.M. Seigneurin, J. Quantitative detection of hepatitis B virus DNA in serum using chemiluminescence: comparison with radioactive solution hybridization assay, $J$ Virol Methods, 1994, 49, 141-151.

7. Liu, J.Y.; Tian, S.J.; Tiefenauer, L.; Nielsen, P.E.; Knoll, W. Simultaneously amplified electrochemical and surface plasmon optical detection of DNA hybridization based on ferrocene-streptavidin conjugates, Anal Chem, 2005, 77, 2756-2761.

8. Wang, R.H.; Minunni, M.; Tombelli, S.; Mascini, M. A new approach for the detection of DNA sequences in amplified nucleic acids by a surface plasmon resonance biosensor, Biosens Bioelectron, 2004, 20, 598-605.

9. Liu, T.; Tang, J.A.; Jiang, L. The enhancement effect of gold nanoparticles as a surface modifier on DNA sensor sensitivity, Biochem Bioph Res Co, 2004, 313, 3-7.
10. Patolsky, F.; Lichtenstein, A.; Willner, I. Amplified microgravimetric quartz-crystalmicrobalance assay of DNA using oligonucleotide-functionalized liposomes or biotinylated liposomes, J Am Chem Soc, 2000, 122, 418-419.

11. Zhang, D.; Chen, Y.; Chen, H. Y.; Xia, X. H. Silica-nanoparticle-based interface for the enhanced immobilization and sequencespecific detection of DNA, Anal Bioanal Chem, 2004, 379, 1025-1030.

12. Lin, X.H.; Wu, P.; Chen, W.; Zhang, Y.F.; Xia X.H. Electrochemical DNA biosensor for the detection of short DNA species of chronic myelogenous leukemia by using methylene blue, Talanta, 2007, 72, 468-471.

13. Zhu, X.L.; Han, K.; Li, G.X. Magnetic nanoparticles applied in electrochemical detection of controllable DNA hybridization, Anal Chem, 2006, 78, 2447-2449.

14. Drummond, T.G.; Hill, M.G.; Barton, J.K. Electrochemical DNA sensors, Nat Biotechnol, 2003, 21, 1190-1199.

15. Wang, J. Nanoparticle-based electrochemical DNA detection, Anal Chim Acta, 2003, 500, 247-257.

16. Gooding, J.J. Electrochemical DNA hybridization biosensors, Electroanalysis, 2002, 14, 1149-1156.

17. Erdem,A. Nanomaterial-based electrochemical DNA sensing strategies, Talanta, 2007, 74, 318-325.

18. Odenthal, K.J.; Gooding, J.J. An introduction to electrochemical DNA biosensors, Analyst, 2007, 132, 603-610.

19. Zhou, N.D.; Wang, J.; Chen, T.; Yu, Z.G.; Li, G.X. Enlargement of gold nanoparticles on the surface of a self-assembled monolayer modified electrode: a mode in biosensor design, Anal Chem, 2006, 78, 5227-5230.

20. Xu, Y.; Ye, X.Y.; Yang, L.; He, P.G.; Fang, Y.Z. Impedance DNA biosensor using electropolymwerized polypyrrole/multiwalled carbon nanotubes modified electrode, Electroanalysis, 2006, 15, 1471-1478.

21. Peng, H.; Soeller, C.; Vigar, N.A.; Caprio, V.; Travas-Sejdic J. Label-free detection of DNA hybridization based on a novel functionalized 
conducting polymer, Biosens Bioelectron, 2007, 22, 1868-1873.

22. Chang, H.X.; Yuan, Y.; Shi, N.L.; Guan, Y,F. Electrochemical DNA biosensor based on conducting polyaniline nanotube array, Anal Chem, 2007, 79, 5111-5115.

23. Jiang, C.; Yang, T.; Jiao, K.; Gao, H.W. DNA electrochemical sensor with poly-1lysine/single-walled carbon nanotubes films and its application for the highly sensitive EIS detection of PAT gene fragment and PCR amplification of NOS gene, Electrochim Acta, 2008, 53, 2917-2924.

24. Nirmal, P.; Kavita, Arora.; Surinder, P. S.; Manoj, K. P.; Harpal, S.; Bansi, D. M. Polypyrrole-polyvinyl sulphonate film based disposable nucleic acid biosensor, Anal Chim Acta, 2007, 589, 6-13.

25. Xu, Y.; Ye, X.Y.; Yang, L.; He, P.G.; Fang, Y.Z. Impedance DNA biosensor using electropolymwerized polypyrrole/multiwalled carbon nanotubes modified electrode, Electroanalysis, 2006, 18 , 1471-1478.

26. Wang, J.; Flechsig, G.U.; Erdem, A.; Korbut, O.; Gründler, P. Label-free DNA Hybridization Based on Coupling of a Heated Carbon Paste Electrode with Magnetic Separations, Electroanalysis, 2004, 16, 928931.

27. Erdem, A.; Ariksoysal, D.O.; Karadeniz, H.; Kara, P.; Sengonul, A.; Sayiner, A.A.; Ozsoz, M. Electrochemical genomagnetic assay for the detection of hepatitis B virus DNA in polymerase chain reaction amplicons by using disposable sensor technology, Electrochem Commun, 2005, 7, 815-820.

28. Authier, L.; Grossiord, C.; Brossier, P.; Limoges, B. Gold nanoparticle-based quantitative electrochemical detection of amplified human cytomegalovirus DNA using disposable microband electrodes, Anal Chem, 2001, 73, 4450-4456.

29. Pedano, M.L.; Rivas, G.A. Adsorption and electrooxidation of nucleic acids at carbon nanotubes paste electrodes, Electrochem Commun, 2004, 6, 10-16.

30. Wang, J.; Liu, G.D.; Jan, M.R. Ultrasensitive electrical biosensing of proteins and DNA: carbon-nanotube derived amplification of the recognition and transduction events, $J A m$ Chem Soc, 2004, 126, 3010-3011.

31. Li, J.; Ng, H.T.; Cassell, A.; Fan, W.D.; Chen, H.; Ye, Q.; Koehne, J.; Han, J.; Meyyappan M. Carbon nanotube nanoelectrode array for ultrasensitive DNA detection, Nano Lett, 2003, 3, 597-602.

32. Li, Z.; Chen, Y.; Li, X.; Kamins, T.I.; Nauka, K.; Williams, R.S. Sequence-Specific LabelFree DNA Sensors Based on Silicon Nanowires, Nan Lett, 2004, 4, 245-247.

33. Lapierre-Devlin, M.A.; Asher, C.L.; Taft, B.J.; Gasparac, R.; Roberts, M.A.; Kelley, S.O. Amplified electrocatalysis at DNA-modified nanowires. Nano Lett 2005, 5, 1051-1055.

34. Zhang,Y.Z.; Ma, H.Y.; Zhang, K.Y.; Zhang, S.J.; Wang, J. An improved DNA biosensor built by layer-by-layer covalent attachment of multi-walled carbon nanotubes, gold Nanoparticles, Electrochim Acta, doi:10.1016/j.electacta.2008.10.052

35. Ma, H.Y.; Zhang, L.P.; Pan, Y.; Zhang, K.Y.; Zhang, Y.Z. A novel electrochemical DNA biosensor fabricated with layer-by-layer covalent attachment of multiwalled carbon nanotubes and gold nanoparticles, Electroanalysis ,2008, 20, 1220-1226.

36. Zhang,Y.Z.; Zhang, K.Y. ; Ma, H.Y. Electrochemical DNA biosensor based on silver nanoparticles / poly(3-(3-pyridyl) acrylic acid)/carbon nanotubes modified electrode, Anal. Biochem. doi:10.1016/j.ab.2008.10.043

37. Yu, A.M.; Chen, H.Y. Electrocatalytic oxidation and determination of ascorbic acid at poly(glutamic acid) chemically modified electrode, Anal Chim Acta, 1997, 344, 181185.

38. Santos, D.P.; Zanoni, M.V.B.; Bergamini, M.F.; Chiorcea-Paquim, A.M.; Diculescu, V.C.; Brett, A.M.O. Poly(glutamic acid) nanofibre modified glassy carbon electrode: Characterization by atomic force microscopy, voltammetry and electrochemical impedance, Electrochim Acta, 2008, 53, 3991-4000.

39. Ou, C.F.; Yuan, R.; Chai, Y.Q.; Tang, M.Y.; Chai, R.; He, X.L. A novel amperometric immunosensor based on layer-by-layer assembly of gold nanoparticles-multi-walled carbon nanotubes-thionine multilayer films on 
polyelectrolyte surface, Anal Chim Acta, 2007, 603, 205-210.

40. Xu, Y.; Jiang, Y.; Cai, H.; He, P.G.; Fang, Y.Z. Electrochemical impedance detection of DNA hybridization based on the formation of M-DNA on polypyrrole/carbon nanotube modified electrode, Anal Chim Acta, 2004, 516, 19-27.

41. Li, X.M.; Xia, J.P.; Zhang, S.S. Label-free detection of DNA hybridization based on poly(indole-5-carboxylic acid) conducting polymer, Anal Chim Acta, 2008, 622, 104110.
42. Qi, H.L.; Li, X.X.; Chen, P.; Zhang, C.X.; Electrochemical detection of DNA hybridization based on polypyrrole/ssDNA/multi-wall carbon nanotubes paste electrode, Talanta, 2007, 72, 1030-1035.

43. Zhang, J.; Song, S.P.; Zhang, L.Y.; Wang, L.H.; Wu, H.P.; Pan, D.; Fan, C.H.; Sequencespecific detection of femtomolar DNA via a chronocoulometric DNA Sensor (CDS): effects of nanoparticle-mediated amplification and nanoscale control of DNA assembly at electrodes, J Am Chem Soc, 2006, 128, 85758580 . 